\title{
Retraction Note to: Surface-functionalized gold nanoparticles mediate bacterial transformation: a nanobiotechnological approach
}

\author{
Saptarshi Chatterjee $\cdot$ Keka Sarkar
}

Published online: 19 April 2015

(C) Springer Science+Business Media Dordrecht 2015

\section{Retraction Note to: Biotechnol Lett (2014) \\ 36:265-271 \\ DOI 10.1007/s10529-013-1360-x}

A paper by Saptarshi Chatterjee and Keka Sarkar that was published in this journal is now retracted due to the deliberate and fraudulent use of data in the paper that had previously appeared in other papers of these two authors and in other papers of Dr Sarkar.

The paper in question is: "Surface-functionalized gold nanoparticles mediate bacterial transformation; a nanobiotechnological approach"; Biotechnology Letters 2014 36:265-271, by S Chatterjee and K Sarkar.

In this paper, the authors used previously published data from other publications of theirs: Chatterjee, Bandyopadhyay and Sarkar "Effect of iron oxide and gold nanoparticles on bacterial growth leading towards biological application" in Journal of Nanobiotechnology 2011 9:34

Two figures in the paper in Biotechnology Letters had been taken from this paper: Fig. $2 \mathrm{c}$ was identical

The online version of the original article can be found under doi:10.1007/s10529-013-1360-x.

S. Chatterjee $\cdot$ K. Sarkar $(\bowtie)$

Department of Microbiology, University of Kalyani,

Calcutta, West Bengal, India

e-mail: keka.micro@gmail.com

S. Chatterjee

e-mail: saptarshi_gcc07@yahoo.co.in to Fig. 3 in the $J$ Nanobiotech paper and Fig. 4 (inset) was identical to Fig. 7 (left). No acknowledgement was given that these figures were identical. In addition, the two figures illustrated results from apparently different experiments.

In addition, Fig. 2c in the Biotech Letters paper was identical to a figure (Fig. 1) in another publication of Dr Sarkar and colleagues: "Bacterial growth response on interaction with iron oxide and gold nanoparticles: Measuring risk to the environment" IEEE 2011 (International Conference on Nanoscience, Technology and Societal Implications; doi 10.1109/ NSTSI.2011.6111986) pages 1-6. Figure $2 b$ in the IEEE publication was also repeated in the Biotechnology Letters paper (Fig. 4) without any acknowledgement of prior publication. Figure $2 \mathrm{a}$ in the Biotechnology Letters paper was also used without modification in another publication of this group: "Localized surface plasmon resonance-based DNA detection in solution using gold-decorated supraparamagnetic $\mathrm{Fe}_{3} \mathrm{O}_{4}$ nanocomposite"; Bandyopadhyay and Sarkar in Analytical Biochemistry 2014 465:156-163.

As we have been made aware of other duplications of data in other papers of Dr Sarkar, and also the use of other people's data and figures as deliberate acts of plagiarism, we have come to the conclusion that this person has knowingly and deliberately used the same data and figures to illustrate results from different scientific experiments in her various publications. Therefore the veracity of the work in the paper of 
Chatterjee and Sarkar that was published in this journal, and indeed in other journals that have been published in the last five years, cannot be vouchsafed and must be regarded as fraudulent or potentially fraudulent. The paper in Biotechnology Letters is therefore retracted.

An inquiry into Dr Sarkar's publications has been conducted by the Vice-Chancellor of her university
(University of Kalyani, West Bengal, India). The charge of plagiarism against Dr Sarkar has been upheld and has resulted in a severe reprimand and restrictions being imposed on her concerning her future in the university.

Colin Ratledge, Editor in Chief 